\title{
Synthesis and Characterization of $\mathrm{MnO}_{2}$ Nanoparticles: Study of Structural and Optical Properties
}

\author{
S.Ganeshan $^{1}$, P.Ramasundari ${ }^{2}$, A.Elangovan ${ }^{3}$, G.Arivazhagan ${ }^{3}$, R.Vijayalakshmi ${ }^{3}$ \\ ${ }^{1}$ Department of Physics, Vivekananda College, Tiruvedakam west, India \\ ${ }^{2}$ P.G. \& Research Department of Physics, S.V.N. College, Madurai, India \\ ${ }^{3}$ P.G. \& Research Department of Chemistry, Thiagarajar College, Madurai, India \\ ${ }^{4}$ P.G. \& Research Department of Physics, Thiagarajar College, Madurai, India \\ *Corresponding Author E-mail Address: sganeshanmdu@gmail.com Tel: 9865059001
}

Available online at: www.isroset.org

Received: 12/Nov/2017, Revised: 25/Nov/2017, Accepted: 20/Dec/2017, Published: 31/Dec/2017

\begin{abstract}
Manganese dioxide nanostructures are of considerable importance in technological applications and have been intensively investigated as promising electrode material in primary/secondary batteries and electrochemical capacitors due to their excellent electrochemical properties, low cost, environmentally benign and ease of preparation. $\mathrm{MnO}_{2}$ nanoparticles are synthesized using Co-Precipitation method. The structural and optical characterization was carried out using Powder X-ray Diffraction method, Scanning Electron Microscope and Energy Dispersive X-ray Spectroscopy, The powder X-ray Diffraction studies revealed the polycrystalline nature of $\mathrm{MnO}_{2}$ nanoparticles. SEM images showed that the particles are almost spherical with varying sizes. Energy Dispersive $\mathrm{X}$-ray Spectroscopy analysis confirms the presence of Manganese and Oxygen.
\end{abstract}

Keywords: $\mathrm{MnO}_{2}$ nanoparticle, Co-Precipitation Method, EDAX, SEM, XRD

\section{INTRODUCTION}

$\mathrm{MnO}_{2}$ can exist in different structural forms $\alpha, \beta, \gamma, \delta, \varepsilon$, and $\lambda$ types and so forth, when the basic structural unit $\left(\left(\mathrm{MnO}_{6}\right)\right.$ octahedron) is linked in different ways. Based on the different $\left(\mathrm{MnO}_{6}\right)$ links, $\mathrm{MnO}_{2}$ can be divided into three categories: the chain like structure, the sheet or layered structure and the 3D structure [1]. Physical Vapour deposition, Chemical vapour deposition, Electrodeposition, Sol-gel process, aerosol processing, mechanical alloying/milling are some of the commonly used methods by which nanoparticles can be synthesized. The Co-precipitation method is commonly employed because it is cost effective and has so many advantages. Nanostructure manganese dioxide has been considered as an ideal electrode material for energy storage, such as super capacitors (also known as electrochemical capacitors) [2-5]. $\mathrm{MnO}_{2}$ is considered as one of the best catalysts due to its low cost and less toxicity, environmental compatibility [6-9].Among many transition metal oxides, Manganese oxide exhibit different forms of which $\mathrm{MnO}_{2}$ is the one of the most attractive oxide due to its unique properties. Manganese dioxide $\left(\mathrm{MnO}_{2}\right)$ is a low band gap, high optical constant semiconductor that exhibits ferroelectric and catalytic properties [10-11].Manganese dioxide nanoparticles synthesized by hydrothermal method [12] and $\alpha-\mathrm{MnO}_{2}$ nanoparticles formed by Co-precipitation method [13] are not $\alpha$ - type. Hence $\mathrm{MnO}_{2}$ nanoparticles were synthesized by Co-precipitation method. By studying powder XRD and SEM techniques to identify the $\mathrm{MnO}_{2}$ nanoparticle formed whether $\alpha-\mathrm{MnO}_{2}$ or not.

This article comprises of four components which describe the contents of the paper in the relevant manner, namely Introduction, Experimental methods, Results and Discussion and Conclusion. The Introduction gives an idea about nature of the compound, methodology and its applications. Experimental methods discuss the synthesis of the nanoparticles by co precipitation method. The results and discussion, gives a brief report on the characterization of the $\mathrm{MnO}_{2}$ nanostructures.. Finally, the conclusion list shows that the results drawn from the characterized data.

\section{MATERIALS AND METHODS}

The Co-precipitation method was performed by using manganese salt like Manganese (II) sulphate of $0.2 \mathrm{M}$ dissolved in double distilled water with continuous stirring at constant temperature of $80^{\circ} \mathrm{C}$. While stirring, $\mathrm{NaOH}$ solution 
was added till the $\mathrm{pH}$ of the solution become 12 . The stirring was continued for 1 hour at a constant temperature of $80^{\circ} \mathrm{C}$. Brown precipitate formed was then filtered and washed with ethanol.

The properties of synthesized $\mathrm{MnO}_{2}$ nanoparticles were determined by X-Ray diffraction method (XPERT-PRO Diffractometer) and Scanning Electron microscope SEM with energy dispersive X-ray Analysis (Philips XL30 ESEM). The properties of formed $\mathrm{MnO}_{2}$ nanoparticles were determined by the aid of UV-Visible Spectroscopy (UV-2400PC Series) in the wavelength range 200 to $900 \mathrm{~cm}^{-1}$. Fourier Transform Infra-Red spectroscopy (FTIR) (Shimazdu) in the wavelength range $400-4000 \mathrm{~cm}^{-1}$.

\section{RESULTS AND DISCUSSION}

\section{X-Ray Diffraction}

Powder XRD analysis has been carried out on the sample to examine the crystalline and to check the purity. Fig 1 depicts $\mathrm{X}$-ray diffraction pattern of manganese oxide nanoparticles synthesized by Co-precipitation method. The peaks at $2 \theta=$ $37^{\circ} 49^{\prime}$ and $41^{\circ} 62^{\prime}$, indicates the formation of tetragonal $\mathrm{MnO}_{2}$. The respective peaks were indexed to (2 111$)$ and (4 2 $0)$ planes which are in good agreement with the JCPDS (0440141) values. The presences of peaks indicate the polycrystalline nature of the $\mathrm{MnO}_{2}$ nanoparticle.

\section{Review: Experimental Values to be tabulated}

\begin{tabular}{|c|c|c|c|c|c|c|}
\hline \multicolumn{2}{|c|}{ Position $2 \theta$} & \multicolumn{2}{|c|}{ d-Spacing } & \multirow[t]{2}{*}{ FWHM } & \multirow[t]{2}{*}{ hkl } & \multirow{2}{*}{$\begin{array}{l}\text { Matched } \\
\text { by }\end{array}$} \\
\hline $\begin{array}{l}D \\
0 \\
0 \\
0 \\
0 \\
0\end{array}$ & $\stackrel{\mathscr{0}}{\tilde{0}}$ & $\begin{array}{l}\vec{D} \\
? \\
? \\
0 \\
0 \\
0\end{array}$ & ڤિ & & & \\
\hline$\frac{a}{\dot{n}}$ & $\frac{n}{n}$ & ले & ते & mे & $\begin{array}{l}\text { ב } \\
\text { d }\end{array}$ & 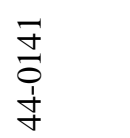 \\
\hline$\frac{\text { তै }}{\dot{\sigma}}$ & 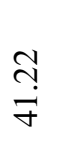 & $\stackrel{6}{a}$ & $\frac{\infty}{\sim}$ & $\begin{array}{l}\frac{0}{5} \\
\text { N̦} \\
0\end{array}$ & $\begin{array}{l}\text { Oे } \\
\text { ̃ } \\
\text { t }\end{array}$ & $\begin{array}{l}\vec{J} \\
\dot{0} \\
\dot{1} \\
\dot{J}\end{array}$ \\
\hline
\end{tabular}

The crystalline size was estimated using Scherer formula $\mathrm{D}=$ $\mathrm{K} \lambda / \beta \operatorname{Cos} \theta$-------- 1

where $\mathrm{D}$ is the crystalline size

$\mathrm{K}$ is the shape factor

$\lambda$ is the Wavelength of X-ray $\theta$ is the Bragg's angle in radians

$\beta$ is the full width half maximum in radians and the crystallite size was in the range of $40-50 \mathrm{~nm}$.

\section{SEM Studies}

The surface morphological studies of nanoparticles have been performed by Scanning Electron Microscope (SEM). The SEM images of $\mathrm{MnO}_{2}$ nanoparticles are portrayed in Fig 2. It was well documented that the surface morphology has significant impact on the performance of nanostructure materials. The uniform distributions of grains are observed in the micrographs. The particles are nearly spherical in shape has uniform size and found to have an average size of about $50 \mathrm{~nm}$. Fig 3 depicts the Energy dispersive X-ray analysis (EDAX) spectrum of $\mathrm{MnO}_{2}$ nanoparticles. The presence of Manganese $(\mathrm{Mn})$ and oxygen $(\mathrm{O})$ are confirmed as observed from the EDAX spectrum, some impurities found in the synthesized $\mathrm{MnO}_{2}$ nanoparticles were eliminated during annealing process at $500^{\circ} \mathrm{C}$. The chemical composition and product purity of the $\mathrm{MnO}_{2}$ nanoparticles have been examined by EDAX. The oxygen storage capacity of the prepared sample has been confirmed by observing a peak due to oxygen in EDAX spectrum.

\section{Optical studies: UV-Visible Spectroscopy:}

In order to determine the optical energy band gap of $\mathrm{MnO}_{2}$ nanoparticles the UV-Vis absorption spectrum was recorded. The sample shows a strong absorption peak $\left(\lambda_{\max }\right)$ at 359.30 $\mathrm{nm}$ in the UV region. Fig. 4 shows the UV-Vis absorption spectrum of $\mathrm{MnO}_{2}$ nanoparticles. This can be attributed to photo excitation of electron from valence band to conduction band. The optical energy band gap (Eg) was estimated as 3.45 eV [14-15].

\section{FTIR Spectroscopy:}

FTIR analysis was carried out in order to ascertain the purity and nature of $\mathrm{MnO}_{2}$ nanoparticles as synthesized by CoPrecipitation method. The FT-IR spectrum was used to identify the functional groups and other impurities present in the final product. The broad band at $3387 \mathrm{~cm}^{-1}$ was believed to be associated with the stretching vibrations of Hydrogen bonded surface water molecules and hydroxyl groups. Additionally the bands at $1627.92 \mathrm{~cm}^{-1}$ and $1327.03 \mathrm{~cm}^{-1}$ corresponds to the existence of large number of residual hydroxyl groups, which imply the $\mathrm{O}-\mathrm{H}$ vibrating mode of traces adsorbed water. The band located at $524.64 \mathrm{~cm}-1$ can be ascribed to the $\mathrm{MnO}$ vibrations of $\mathrm{MnO}_{2}$ nano powder. The spectrum does not show the organic groups found in the $\mathrm{MnO}_{2}$ nanoparticles. 


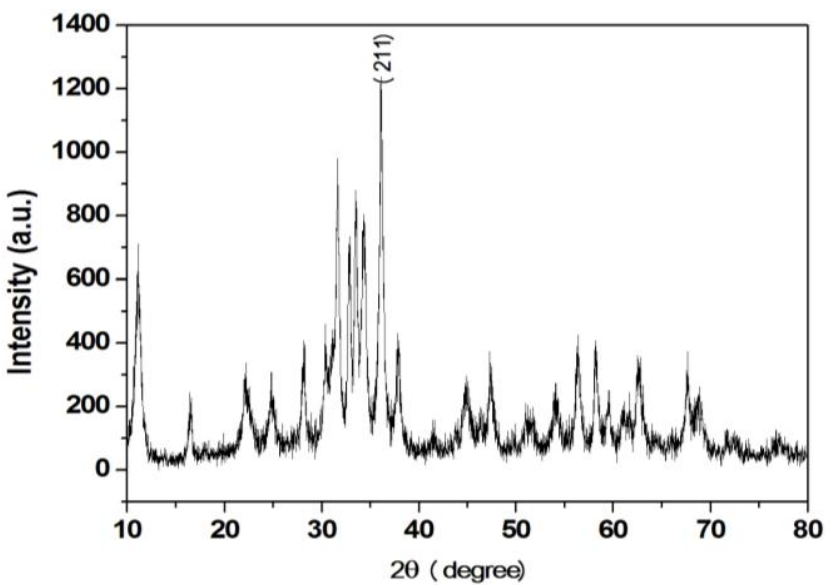

Fig 1. XRD images of as prepared $\mathrm{MnO}_{2}$ nanoparticles
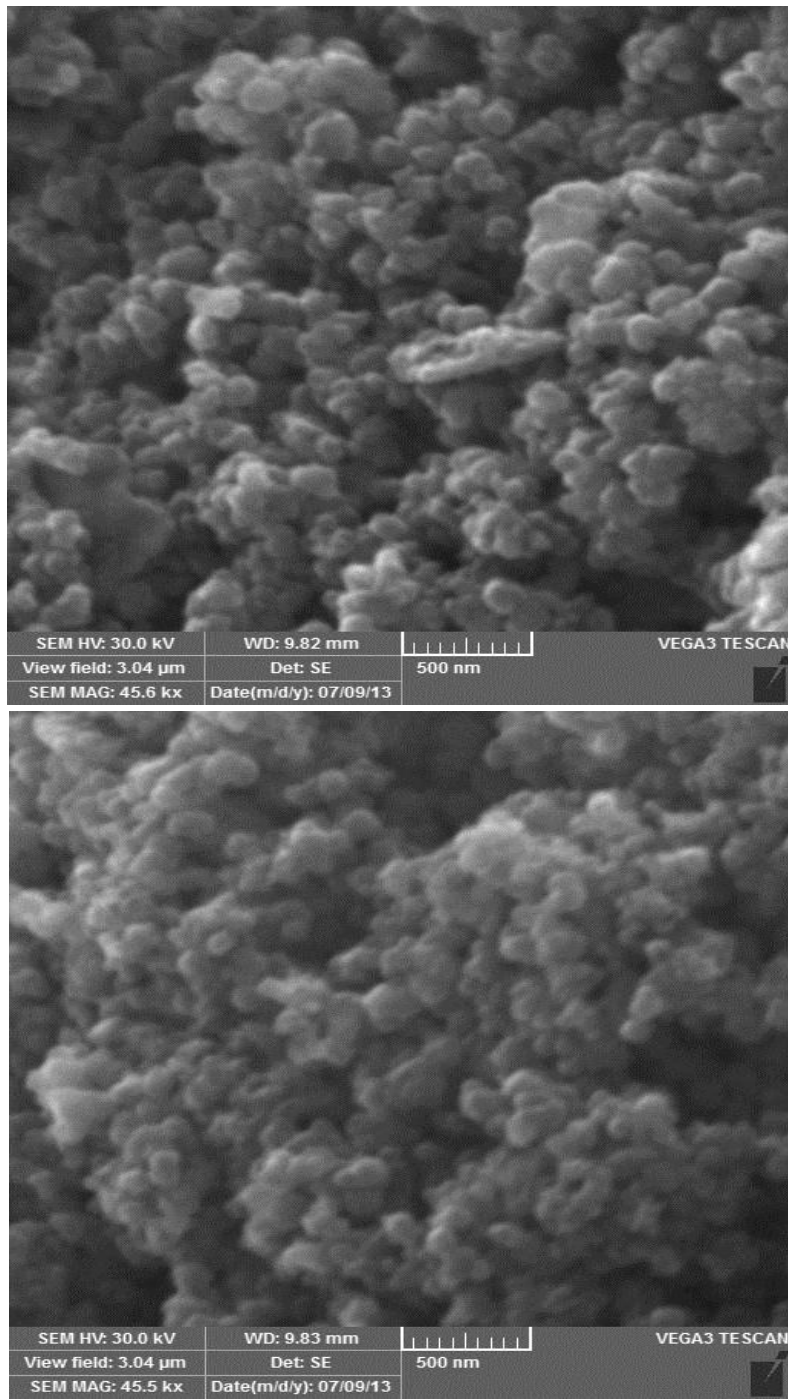

Fig. 2. SEM images of as prepared $\mathrm{MnO}_{2}$ nanoparticles

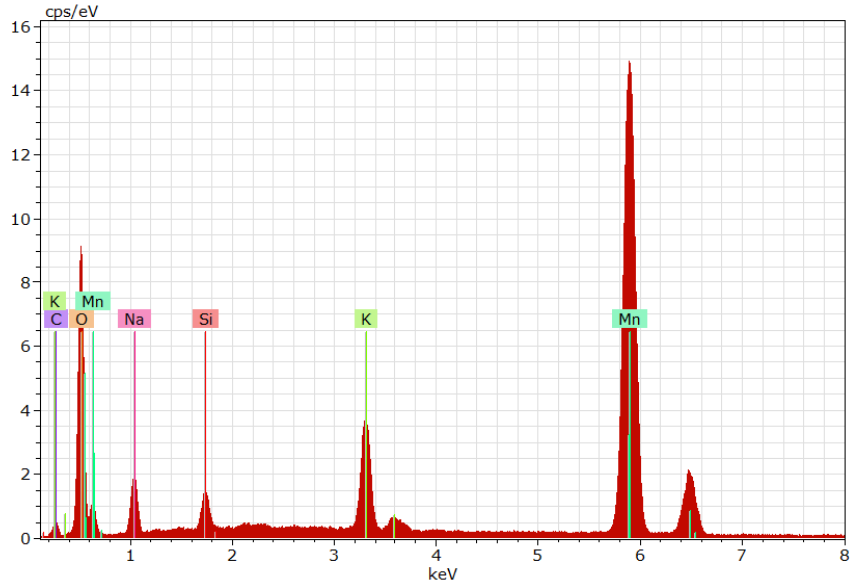

Fig 3. EDAX Spectrum of $\mathrm{MnO}_{2}$ nanoparticles

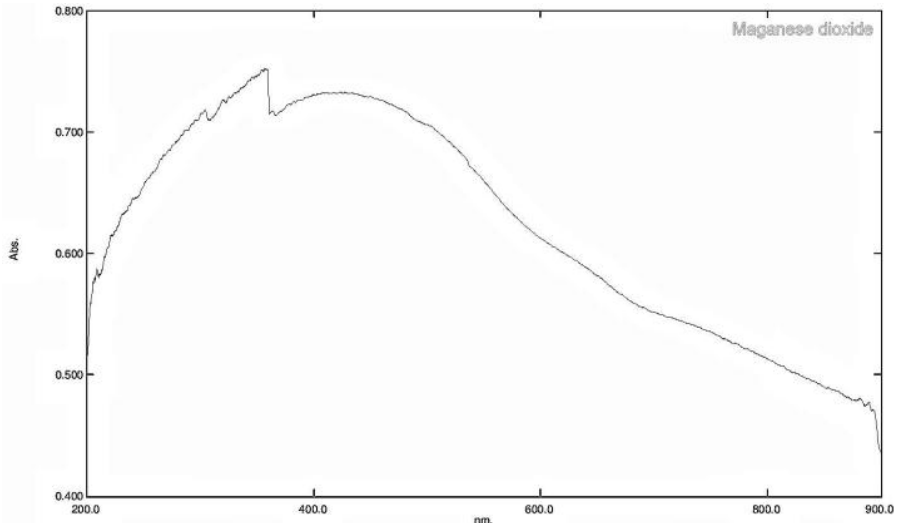

Fig 4: UV-Visible Spectra of Manganese oxide nanoparticles

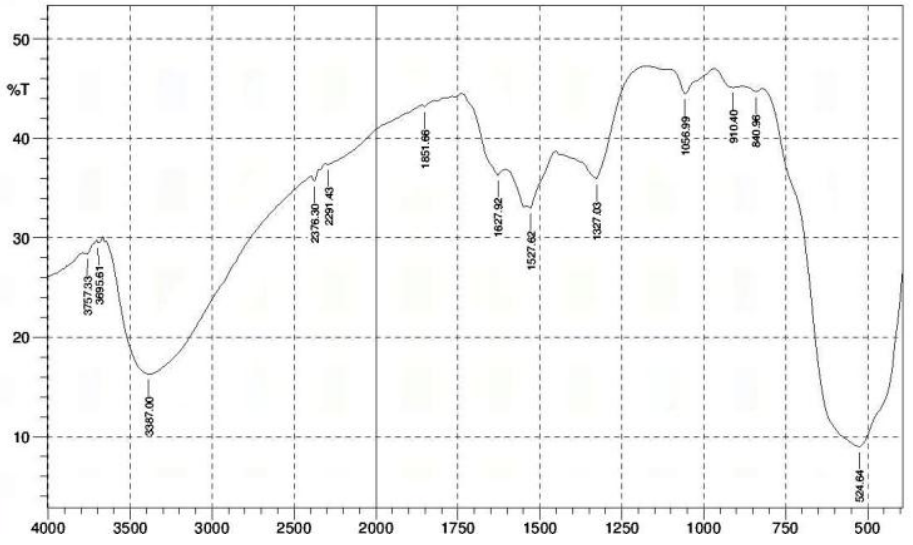

Fig 5: FT-IR Spectrum of $\mathrm{MnO}_{2}$ nanoparticles

\section{CONCLUSION}

$\mathrm{MnO}_{2}$ nanoparticles have been successfully synthesized by Co-Precipitation method. The nanoparticles are characterized by XRD, SEM with EDAX, UV and FTIR techniques. The 
results showed that the parameters like the effect of $\mathrm{pH}$ and contact time will play a very important role on the adsorption. The as prepared $\mathrm{MnO}_{2}$ nanoparticle showed a good ability to remove organic pollutants and heavy metal ions and is expected to be useful in many other applications. The as prepared $\mathrm{MnO}_{2}$ nanoparticles can be annealed and analyzed for various temperatures, further electric and magnetic properties can be studied for the as prepared and annealed structures in the future.

\section{REFERENCES}

[1]. Y.Chen,Y.Hong,Y.Ma and J.Li, "Synthesis and formation mechanism of urchin like nano/micro hybrid $\alpha$ - $\mathrm{MnO}_{2}$ ", Journal of Alloys and Compounds, Vol.490, p.p. 2880- 2881 , (2002)

[2]. X.Lang, A.Hirata, T.Fujita and M.Chem, "Nanoporous Metal/Oxide Hybrid Electrodes for Electrochemical Supercapacitors", Nature Technology, Vol.6, No.4,2011, pp.232236

[3]. [3] W.Wei , X.Cui, W.Chen and D.G.Ivey, "Manganese OxideBased Materials as Electrochemical Supercapacitor Electrodes," Chemical Society Reviews, Vol.40, No.3, 2011, pp.1697-1721

[4]. W.Li, G.li, J.Sun,R.Zou,K.Xu,Y.Sun,Z.Chem,J.Yang and J.Hu , "Hierarchical Heterostructures of $\mathrm{MnO}_{2}$ Nanosheets or Nanorods Grown on Au-Coated $\mathrm{Co}_{3} \mathrm{O}_{4}$ Porous Nanowalls for High-Performance Pseudocapacitance," Nanoscale, Vol.5, No.7, (2013), pp.2901- 2908.

[5]. W.Li, Q.Liu, Y.Sun, J.Sun,R.Zou, G.li,K.Hu,G.Ma, J.Yang, ,Z.Chem, and J.Hu, " $\mathrm{MnO}_{2}$ Ultralong Nanowires with Better Electrical Conductivity and Enchanced Supercapacitor Performances," Journal of Materials Chemistry, Vol.22, No.30, (2012), pp 14864- 14867

[6]. M.M.Atabaki,R.Kovacevic, Electron Matter,Lett 9,133 (2013)

[7]. C.Hu,T.Tsou, Electrochemistry Communications, 4, 105 (2002)

[8]. M.Topuin,T.Brousse, D.Belenger, Chemistry of Materials , 14, 3946 (2002)

[9]. L.X.Zhang,Y.Z.Wang,H.F.Jiu, Y.L.Wang, V.X. Sun,Z.Li, Electron Matter lett.10, 439(2014)

[10]. Shao-Horn Y, Hackney SA, Johnson CS, Thackeray MM.J. Electrochem Soc 1998;145; 582-589

[11]. Zoltowski P, Drazic DM,Vorkapic L, J Appl Electrochem 1993;3:271-283

[12]. M.Senthilkumar, Balamurugan and B.G. Jeyaprakash ,Hydrothermal Synthesis of $\mathrm{MnO}_{2}$ Nanoparticles using Teflon Leined Autoclave, Research Journal of Pharmaceutical,Biological and Chemical Sciences, Vol.4 pp 1627-1632(2013)

[13]. Harish Kumar, Manisha and Poonam Sangwan, "Synthesis and Characterization of $\mathrm{MnO}_{2}$ Nanoparticles using Co-Precipitation Technique. Vol.3, 3 (2013) pp155-160

[14]. R. N. Iskenderov, I. A. Drabkin, T. L. Emel'yanova and Ya. Ksendzov, Fiz. Tverd. Tela 10, 2573 (1968). [Sov.Phys.-Solid State 10, 2031 (1969)].

[15]. C. Franchini, V. Bayer, R. Podloucky, J. Paier, G. Kresse, Phys. Rev. B 72, 045132 [6 pages] (2005). 